\title{
(5)
}

AL-DZIKRA

Jurnal Studi Ilmu Al-Qur'an Dan Al-Hadits

http://ejournal.radenintan.ac.id/index.php/al-dzikra

Volume 12, No. 1, Juni Tahun 2018, Halaman 51 - 74

DOI://dx.doi.org/10.24042/al-dzikra.v12i1.2925

\section{HADIS GADIR KHUM \\ DALAM PANDANGAN SYIAH DAN SUNNAH}

\author{
Izzuddin Washil \\ IAIN Syekh Nurjati Cirebon \\ izzuddinwashil@gmail.com \\ Ahmad Khoirul Fata \\ IAIN Sultan Amai Gorontalo \\ cakfata@gmail.com
}

\section{Abstrak}

Hadis Gadir Khum yang menjadi titik tolak perpisahan mazhab Sunni dan Syiah juga terdapat dalam kitab-kitab hadis utama kaum Sunni. Seperti kaum Syiah, para ulama Sunnah juga mengakui keabsahan derajat hadis-hadis tersebut. Bahkan hadishadis itu dianggap mutawatir. Namun demikian, antara kaum Syiah dan Sunni memiliki pemahaman yang berbeda terhadap hadis-hadis tersebut. Perbedaan terjadi dalam memahami kata mawlā. Sunni berpendapat bahwa kata itu bermakna pelindung/penolong, sementara Syiah berpendapat bahwa kata itu bermakna khalifah/pemimpin. Perbedaan pemahaman ini membawa kedua kelompok tersebut terlibat dalam pertengkaran sepanjang sejarah Islam. Namun demikian, banyak kalangan di Sunni dan Syiah yang berupaya membangun hubungan harmonis dengan mencari hal-hal yang sama di antara keduanya. Sematamata untuk kepentingan ukhuwwah Islāmiyyah dan kejayaan umat Islam.

Kata Kunci: Syiah, Sunni, Hadis Gadir Khum, Mawla. 


\section{A. Pendahuluan}

Hadis Gadir Khum, ${ }^{1}$ hadis tentang ke-mawla-an Ali bin Abi Thalib yang diumumkan Nabi Saw di hadapan kaum Muslimin sekembalinya dari haji wada' di lembah Khum menarik dikaji karena hadis ini terdapat dalam kitab-kitab hadis kalangan Sunnah. ${ }^{2}$ Seperti kita tahu, hadis Gadir Khum adalah hadis pegangan utama

${ }^{1}$ Ghadīr Khūm adalah nama sebuah tempat di dekat al-Juhfah. Ia merupakan tempat perlintasan bagi jalan-jalan menuju Madinah, Mesir, Irak, Suriah, dan Najd. Tempat ini memiliki sumber air dan pepohonan. Inilah tempat banyak kafilah beristirahat dalam perjalanan mereka. Hadis Ghadīr Khüm, sebagian kalangan menyebutnya hadis al-Ghadīr, adalah hadis tentang perkataan Nabi Saw. bahwa Ali bin Abi Thalib adalah mawlā-nya yang disampaikan di suatu tempat yang bernama Ghadìr Khüm tersebut.

${ }^{2}$ Sunnah adalah kependekan dari Ahl al-Sunnah wa al-Jama'ah. Ini adalah nama sebuah mazhab dalam Islam. Al-Bagdadi (w. 429 H.) dalam al-Farq bayn al-Firāq menggolongkan mazhab ini sebagai kelompok yang selamat. Ia menukil satu riwayat bahwa yang dimaksud Ahl al-Sunnah wa al-Jama'ah adalah golongan yang mengikuti Nabi Saw. dan para Sahabatnya. Untuk menjelaskan golongan ini, ia merinci sembilan ciri yang dimiliki golongan ini. Di antaranya di bidang akidah, menerima sifat-sifat Allah dan sifat-Nya yang azali, menolak paham Qadariyyah dan Mu'tazilah, meyakini dapat melihat Allah dangan pandangan mata, meyakini kebangkitan manusia dari kubur, meyakini pertanyaan di alam kubur, meyakini adanya sïirāt, syafā'ah, dan ampunan dosa selain syirik. Di bidang politik, mengakui kepemimpinan khalifah Abu bakar, Umar bin Khaththab, Utsman bin Affan, dan Ali bin Abi Thalib, mewajibkan ketaatan kepada penguasa selama tidak memerintahkan kepada maksiat. Lihat al-Bagdadi, al-Farq bayn al-Firāq (Beirut: Dār al-Kutub al-'Ilmiyyah, tt.), h. 240-244.

Terminologi Ahl al-Sunnah wa al-Jama'ah (Aswaja) secara baku belum dijumpai dalam referensi lama (marāji' awwaliyyah). Pada masa al-Asy'ari (w. 324 H.) pun, yang oleh banyak kalangan dianggap sebagai pendiri mazhab Aswaja, belum ditemukan istilah tersebut. Pengenalan istilah Aswaja sebagai suatu aliran dalam Islam baru nampak pada aṣhāb al-Asy 'āri, seperti al-Baqillani (w. 403 H.), al-Bagdadi (w. 429 H.), al-Juwaini (w. 478 H.), al-Ghazali (w. 505 H.), al-Syahrastani (w. 548 H.), al-Razi (w. 606 H.). Meskipun demikian, mereka tidak secara tegas membawa bendera Aswaja sebagai mazhab. Pernyataan tegas tentang Aswaja baru dijumpai pada pendapat al-Zabidi (w. 1205 H.): "Jika disebutkan Ahl al-Sunnah, maka yang dimaksud adalah penganut Asy'ari dan Maturidi."

Dalam konteks kekinian, Said Agiel Siradj memberi definisi Ahl alSunnah wa al-Jama'ah sebagai orang-orang yang memiliki metode berpikir keagamaan yang mencakup semua aspek kehidupan yang berlandaskan atas dasar-dasar moderasi, menjaga keseimbangan dan toleran. Lebih lanjut baca Said Agiel Siradj, Ahlussunnah wal Jama'ah dalam Lintas Sejarah (Yogyakarta: LKPSM, 1997), h. 18-21. 
kalangan Syiah $^{3}$ yang mempunyai pendirian bahwa sebelum wafat Nabi Saw. telah mengader dan menunjuk penggantinya, yakni Ali bin Abi Thalib, untuk meneruskan risalah kenabiannya. ${ }^{4}$

Jika kalangan Syiah meriwayatkan hadis ini, wajar belaka mereka meriwayatkannya karena hadis ini adalah tonggak utama identitas syiah mereka. ${ }^{5}$ Namun jika kalangan Sunni yang meriwayatkannya, pertanyaan yang segera muncul adalah, apakah mereka juga mengakui kepemimpinan Ali bin Abi Thalib, Bukankah mereka berpendapat bahwa Nabi Saw semasa hidupnya tak pernah memikirkan siapa penggantinya kelak yang akan mengurus umat jika dirinya wafat $?^{6}$ Lebih jauh, jika mereka juga mengakui kesahihan hadis ini, bukankah ini dapat berarti perbedaan utama Syiah dan Sunnah sudah tidak ada lagi, Ataukah mereka mempunyai pemahaman lain terhadap hadis ini?

Tulisan ini, selain mengetengahkan pemahaman kalangan Syiah terhadap hadis Gadir Khum, juga akan mengemukakan pemahaman kalangan Sunni terhadap hadis yang sama. Jika terdapat

${ }^{3}$ Menurut al-Bagdadi, pada zaman Ali bin Abi Thalib terdapat satu golongan Syiah yang bernama Saba'iyyah. Mereka secara jelas menampakkan kebid'ahan mereka dengan mengatakan kepada Ali bin Abi Thalib, "engkaulah Tuhan”, lalu Ali membakar mereka. Golongan ini tidak termasuk golongan umat Islam karena telah menuhankan Ali bin Abi Thalib. Setelah zaman Ali, Syiah terbagi menjadi empat kelompok, Zaydiyyah, Imāmiyyah, Kaysāniyyah, dan Gulāt. Masing-masing dari keempat kelompok tersebut terbagi pula menjadi beberapa kelompok kecil. Semua kelompok Syiah Gulāt (yakni mereka yang menuhankan para Imam, menghalalkan apa yang diharamkan syari'ah, dan menggugurkan kewajiban syari'ah) tidak termasuk kelompok Islam. Sementara kelompok Zaydiyyah dan Imämiyyah dapat dimasukkan ke dalam golongan umat Islam. Lihat al-Bagdadi, al-Farq Bayn al-Firāq..., h. 16-17.

${ }^{4}$ Tentang hal ini lihat Ahmad Khoirul Fata, "Hadis Gadir Khum, Mandat Kepemimpinan Untuk Ali," Jurnal Studi Islam, Vol II No 3, 2017.Juga Ahmad Khoirul Fata, "Menyoal Hadis Duabelas Khalifah," Al-Qalam, Vol 30, No 3, 2013

${ }^{5}$ Murtadha Muthahhari, Imamah dan Khilafah, penerjemah: Satrio Pinandito, cet. 1 (Jakarta: Firdaus, 1991), h. 67-90; M. Quraish Shihab, Sunnah Syiah Bergandengan Tangan! Mungkinkah? Kajian atas Konsep Ajaran dan Pemikiran, cet. IV [edisi revisi] (Tangerang: Lentera hati, 2014), h. 63; Abu Bakar Aceh, Syiah Rasionalisme dalam Islam, edisi kelima (Solo: Ramadhani, 1988), h. 18.

${ }^{6}$ M. Baqir Shadr, Suksesi Kepemimpinan Pasca Nabi, penerjemah: M. Syukri (ttp.: Yayasan Islam al-Baqir, 1996), h. 16-25; O. Hashem, Saqifah Awal Perselisihan Umat, cet. 3 (Jakarta: al-Muntazhar, 1994), h. 212. 
kesamaan pemahaman antara keduanya, di manakah letak persamaannya? Dan jika terdapat perbedaan antara keduanya, di manakah letak perbedaannya? Pertanyaan selanjutnya, apakah keduanya tidak mungkin dipertemukan dan diakrabkan karena perbedaannya terlalu jauh dan bersifat ușūlì, ataukah keduanya mungkin dipertemukan dan diakrabkan karena perbedaannya tidak terlalu jauh dan hanya bersifat fur $\bar{u} ' \vec{\imath}$ ?

Sebelum menjawab beberapa pertanyaan ini, tulisan ini terlebih dahulu akan menampilkan hadis Gadir Khum dalam beberapa kitab hadis baik di kalangan Syiah maupun Sunni. Setelah itu, tulisan ini akan mengemukakan pemahaman kedua golongan ini terhadap hadis Gadir Khum untuk mendapatkan titik-titik persamaan dan perbedaan keduanya, dan untuk menjajaki kemungkinan dilakukannya pendekatan dan pengakraban keduanya demi tegaknya ukhuwwah Islämiyyah dan demi kejayaan seluruh umat Muslim.

\section{B. Teks Hadis Gadir Khum}

Hadis Gadir Khum tidak hanya terdapat dalam kitab hadis kalangan Syiah, ${ }^{7}$ namun juga termuat dalam kitab hadis kalangan Sunni. Di kalangan Sunni, hadis itu terdapat dalam kitab Musnad Ahmad, al-Mustadrak 'Ala al-Sahihain, Sahih Muslim, Sunan alNasa'i al-Kubra, Sunan al-Tirmidhi, Sunan Ibn Majah, dan lainlain. Dalam Sunan al-Tirmidhi, bunyi hadis ini sebagai berikut:

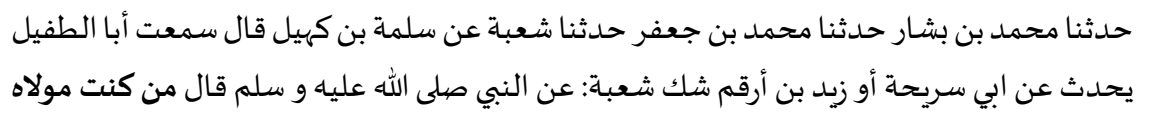

${ }^{7}$ Untuk sanad dan matan hadis Gadir Khum dari jalur Syiah, bisa dilihat, di antaranya, dalam tulisan M. B. Ansari, What Happened? Peristiwa Seputar Haji Terakhir. Dalam tulisannya ini, ia menyebutkan tiga jalur periwayatan hadis Gadir Khum, yakni (1) riwayat dari Imam Muhammad Baqir; (2) riwayat dari Zaid bin Arqam; (3) riwayat dari Huzaifah bin al-Yaman. Mengenai teks khutbah Nabi Saw. di Gadir Khum yang ada di buku ini terlihat lebih panjang dari teks khutbah Nabi Saw. yang diriwayatkan kalangan Sunni. Lihat M. B. Ansari, What Happened? Peristiwa Seputar Haji Terakhir, (Jakarta: Al-Huda, tt.), h. 64-146. Lihat juga A. Syarafuddin al-Musawi, al-Murāja'āt, cet. 2 (Beirut: ttp., 1982), h. 284-294. 


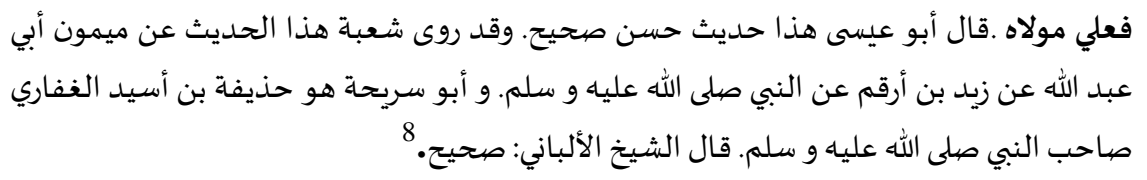

Muhammad bin Basyar menceritakan kepada kami, Muhammad bin Ja'far menceritakan kepada kami, Syu'bah menceritakan kepada kami dari Salamah bin Kahil yang berkata, Saya mendengar Abu Thufail menceritakan dari Abu Sarihah atau Zaid bin Arqam yang diduga Syu'bah, dari Nabi Saw.: Siapa yang (menjadikan) aku sebagai mawlā-nya, maka Ali adalah mawlā-nya. Abu Isa berkata, hadis ini hasan sahih. Syu'bah meriwayatkan hadis ini dari Maimun Abi Abdillah dari Zaid bin Arqam dari Nabi Saw. Abu Sarihah adalah Hudzaifah bin Asid al-Ghiffari, sahabat Nabi. Syaikh alAlbani berkata: Sahih.

Dalam Sunan al-Tirmidhi ini, tanpa didahului perkataan apa pun, Nabi Saw. langsung menyatakan man kuntu mawläh fa 'aliyyun mawlāh. Hadis ini sangat ringkas jika dibanding dengan hadis serupa dalam riwayat yang lain. Dalam Sunan al-Nasa'i berikut, sebelum menyatakan man kuntu mawlāh fahāda mawlāh, Nabi memulainya dengan pertanyaan kepada para Sahabatnya tentang kemawlā-annya bagi setiap Muslim:

أخبرنا قتيبة بن سعيد قال أخبرنا بن أبي عدي عن عوف عن ميمون أبي عبد الله قال زيد بن أرقم: قام

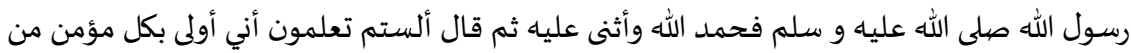
نفسـ قالوا بلى نحن نشهد لأنت أولى بكل مؤمن من نفسه قال فإني من كنت مولاه فهذا مولاه أخذ أخد 9 بيد علي.

Qutaibah bin Said mengabarkan kepada kami, ibn Abi Adi mengabarkan kepada kami dari 'Auf dari Maimun Abi Abdillah, Zaid bin Arqam berkata, Rasulullah berdiri lalu memanjatkan puji syukur kepada Allah lalu bersabda, Apakah kalian tidak mengetahui bahwa saya lebih utama bagi setiap Mukmin daripada diri mereka sendiri. Mereka menjawab, benar, kami bersaksi, engkau lebih utama bagi setiap Mukmin daripada diri mereka sendiri. Nabi bersabda,

${ }^{8}$ Imam al-Tirmidhi, Sunan al-Tirmidhi, juz 5, h. 633 (Maktabah Shamilah).

${ }^{9}$ Imam al-Nasa'i, Sunan al-Nasa'i al-Kubra, juz 5, h. 131 (Maktabah Shamilah). 
Siapa yang aku adalah mawla-nya, maka ini adalah mawla-nya, seraya memegang tangan Ali.

Dalam Sunan Ibn Majah, perawi menambahkan keterangan mengenai posisi Ali di samping Nabi sebagaimana posisi Harun di samping Musa, dan tambahan perkataan lain mengenai keutamaan Ali, setelah perkataan man kuntu mawlāh fa'aliyyun mawlāh:

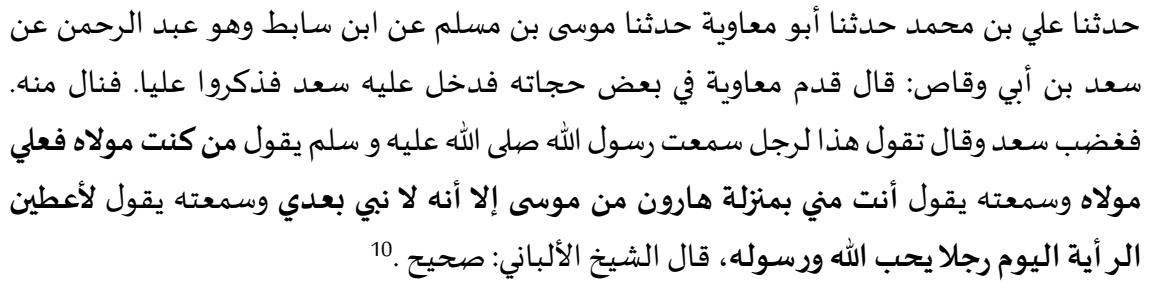

Ali bin Muhammad menceritakan kepada kami, Abu Mu'awiyah menceritakan kepada kami, Musa bin Muslim menceritakan kepada kami, dari Ibn Sabit, yakni Abdurrahman, dari Sa'd bin Abi Waqqash, Mu'awiyah mengemukakan sebagian hujjahnya, lalu Sa'd masuk dan mereka menyebut Ali. Lalu Sa'd marah dan berkata, anda berkata demikian untuk seseorang yang saya dengar Rasulullah bersabda, Siapa yang aku mawla-nya, maka Ali adalah mawla-nya. Dan saya mendengar beliau bersabda, Engkau di sisiku sama seperti Harun di sisi Musa hanya saja tidak ada nabi setelahku. Dan Nabi bersabda, Saya akan memberi pandangan pada seseorang yang mencintai Allah dan Rasul-Nya. Syaikh al-Albani berkata, sahih.

Dalam Musnad Ahmad, setelah perkataan man kuntu mawlah fa'aliyyun mawlāh terdapat tambahan doa bagi kewaliyyan Ali:

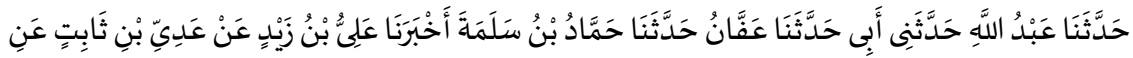

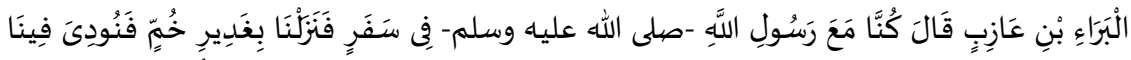

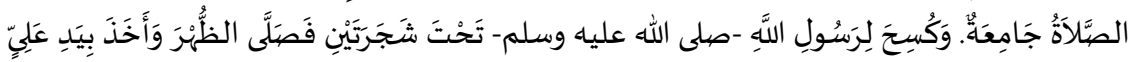

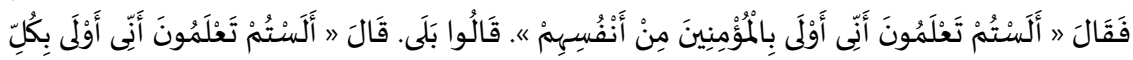

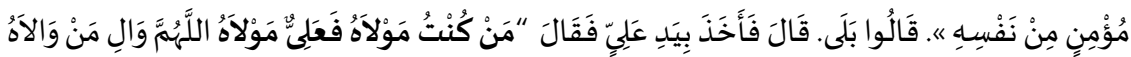

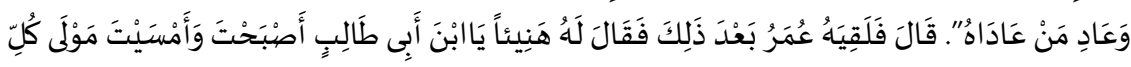

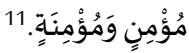

${ }^{10}$ Imam Ibn Majah, Sunan Ibn Majah, juz 1, h. 45 (Maktabah Shamilah).

${ }^{11}$ Imam Ahmad, Musnad Ahmad, juz 40, h. 145 (Maktabah Shamilah). 
Abdullah menceritakan kepada kami, bapakku mencerita- kan kepadaku, Affan menceritakan kepada kami, Hammad bin Salamah menceritakan kepada kami, Ali bin Zaid menceritakan kepada kami, dari Adi bin Tsabit, dari Barra' bin Azib, kami bersama Rasulullah Saw. dalam sebuah perjalanan. Lalu kami tiba di Gadir Khum, dan melakukan shalat jama'ah Dzuhur di bawah dua pohon. Lalu Rasul mengambil tangan Ali dan berkata, Apakah kalian tidak mengetahui bahwa aku lebih utama bagi kaum Mukminin daripada diri mereka sendiri. Mereka menjawab, benar. Nabi bersabda, Apakah kalian tidak mengetahui bahwa aku lebih utama bagi setiap Mukmin daripada diri mereka sendiri. Mereka menjawab, benar. Lalu Nabi bersabda seraya memegang tangan Ali, Siapa yang aku adalah mawla-nya, maka Ali adalah mawla-nya. Ya Allah cintailah siapa yang mencintainya, musuhilah siapa yang memusuhinya. Lalu Umar menghampiri Ali bin Abi Thalib dan berkata, selamat wahai putra Abi Thalib, anda sekarang adalah mawla setiap mukmin dan mukminah.

Dalam al-Mustadrak, perkataan man kuntu mawlāh fahạd̄a waliyyuhu diucapkan Nabi setelah wasiatnya tentang thaqalain:

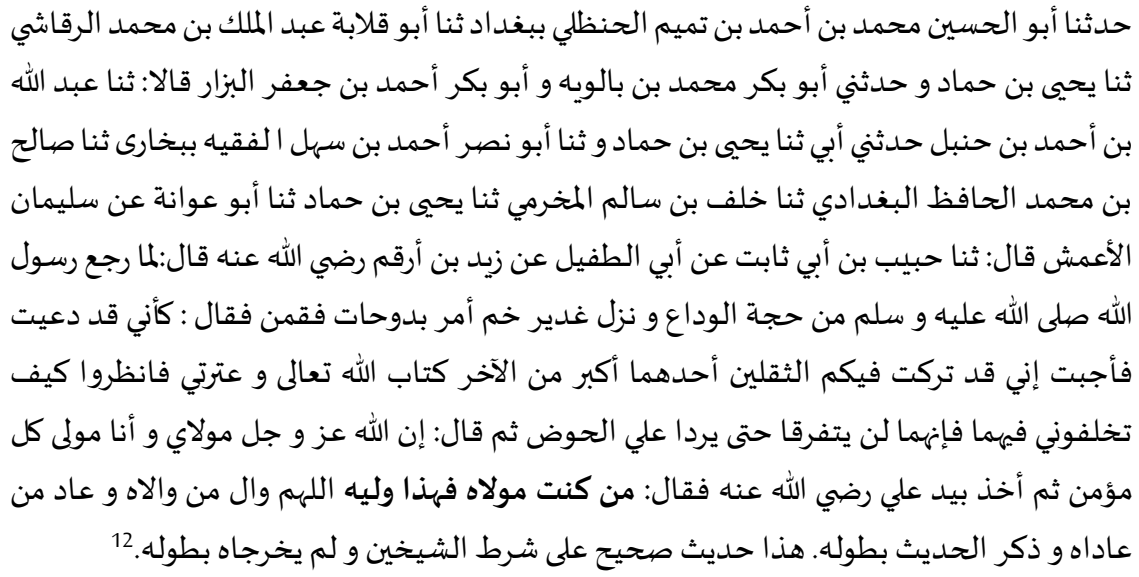

Abu al-Husain Muhammad bin Ahmad bin Tamim al-Handzali menceritakan kepada kami, Abu Qalabah Abd al-Malik bin Muhammad al-Raqasyi menceritakan kepada kami, Yahya bin

${ }^{12} \mathrm{Al}-$ Hakim, al-Mustadrak 'alā al-Șahīhain, juz 3, h. 118 (Maktabah Shamilah). Lihat juga Al-Hakim, al-Mustadrak 'alā al-Ṣahī̄hain, juz 3, h. 613 (Maktabah Shamilah). Sementara, dalam Sahih Muslim, Nabi hanya menjelaskan wasiatnya tentang taqalain (wasiat Nabi Saw. tentang dua hal: Kitab Allah dan Ahli Baitnya), dan tidak menyatakan man kuntu mawlāh fa'aliyyun mawlāh. Lihat Imam Muslim, Sahih Muslim, juz 4, h. 1873 (Maktabah Shamilah). 
Hamad menceritakan kepaa kami, Abu Bakar Muhammad bin Balwih dan Abu Bakar Ahmad bin Ja'far al-Bazzar berkata, Abdullah bin Ahmad bin Hanbal menceritakan kepada kami, bapakku menceritakan kepada kami, Yahya bin Hamad menceritakan kepada kami, Abu Nashr Ahmad bin Sahl al-Faqih menceritakan kepada kami, Shalih bin Muhammad al-Hafidz menceriatakan kepada kami, Khalaf bin Salim al-Makhrami menceritakan kepada kami, Yahya bin Hamad menceritakan kepada kami, Abu Awanah menceritakan kepada kami dari Sulaiman al-A'masy, Habib bin Abi Tsabit menceritakan kepada kami, dari Abu Thufail dari Zaid bin Arqam: Ketika Rasulullah kembali dari haji Wada' dan sampai di Gadir Khum, beliau memerintahkan berhenti dan bersabda, Aku tinggalkan kepada kalian dua pusaka besar, salah satunya lebih besar dai yang lain, yakni Kitabullah dan keluargaku. Perhatikan, bagaimana kalian menyikapinya. Keduanya tidak akan berpisah hingga menemuiku di telaga al-Haudh. Lalu beliau bersabda, sesungguhnya Allah Swt. adalah mawla-ku, dan aku mawla setiap mukmin, lalu Rasulullah mengambil tangan Ali dan bersabda, Siapa yang aku adalah mawla-nya, maka ini adalah waliy-nya. Ya Allah, cintailah siapa yag mencintainya, dan musuhilah siapa yang memusuhinya. Ia menyebut hadis ini dalam riwayat panjang. Ini hadis sahih menurut persyaratan dua syaikh (Bukhari-Muslim) namun keduanya tidak meriwayatkan sepanjang matan ini.

Dan dalam al-Nasa'i al-Kubra, Nabi langsung bersabda man kuntu mawlāh fa'aliyyun mawlāh:

$$
\begin{aligned}
& \text { أخبرني زكريا بن يحيى قال حدثنا نصر بن علي قال أخبرنا عبد الله بن داود عن عبد الواحد بن أيمن } \\
& \text { عن أبيه أن سعدا قال قال رسول الله صلى الله عليه و سلم: من كنت مولاه فعلي مولاه }
\end{aligned}
$$

Zakaria bin Yahya mengabarkan kepadaku, Nashr bin Ali menceritakan kepada kami, Abdullah bin Dawud mengabarkan kepada kami dari Abdul Wahid bin Aiman dari bapaknya, Sa'd berkata, Nabi Saw. bersabda: Siapa yang aku adalah mawla-nya, maka Ali adalah mawla-nya.

Dari sekian riwayat hadis Gadir Khum yang dikemukakan dalam beberapa kitab hadis di atas, semuanya mengandung matan "man kuntu mawlāh fa' 'aliyyun mawlāh" dengan sedikit perbedaan redaksi. Misalnya, 'man kuntu mawlāh fahāḍa waliyyuh', atau 'man kuntu mawlāh fahāọā mawlāh'. Meskipun diriwayatkan dari banyak jalur sanad, hadis ini perlu diteliti kualitas sanad dan matan-nya agar bisa dipastikan derajat kesahihannya. 


\section{Otentisitas Hadis Gadir Khum: Kritik Sanad dan Matan}

Dari segi sanad, untuk mendapatkan kepastian keotentikan hadis Gadir Khum, seharusnya semua jalur sanad hadis ini diteliti satu per satu. Namun karena fokus tulisan ini bukan pada masalah kritik sanad dan matan, tulisan ini hanya akan melakukan kritik sanad hadis riwayat al-Nasa'i dari Sa'd bin Abi Waqqash sebagai sampel saja. Hadis Gadir Khumriwayat al-Nasa'i dari Sa'd bin Abi Waqqash mempunyai sanad sebagai berikut:

$$
\begin{aligned}
& \text { أخبرني زكريا بن يحيى قال حدثنا نصر بن علي قال أخبرنا عبد الله بن داود عن عبد الواحد بن أيمن }
\end{aligned}
$$

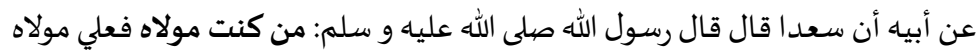

Kualitas perawi: ${ }^{13}$

1. Zakariya bin Yahya. Dalam kitab Mașihah al-Nasā'i disebutkan ia adalah seorang yang berderajat siqah.

2. Nasr bin 'Ali. Dalam kitab Ruwah al-Tahdibin disebutkan bahwa nama lengkapnya adalah Nashr bin Ali bin Nashr bin Ali bin Shuhban bin Abi al-Azdi al-Jahdhamiy Abu Amr al-Bashri. Ia wafat pada tahun $250 \mathrm{H}$ di Basrah. Dalam periwayatan hadis ia termasuk tingkatan ke 10. Menurut Ibn Hajar ia memiliki derajat siqah. Sedangkan menurut al-Dzahabi ia memiliki derajat alHāfiz. Adapun dalam pandangan Abu Hatim ia lebih siqah daripada Falas dan lebih hăfiz.

3. 'Abdullah bin Dawud. Dalam Kitab Ruwāt al-Tahżībīn disebutkan bahwa nama lengkapnya adalah Abdullahbin Dawud bin Amir al-Hamdani al-Sya'bi Abu Abd al-Rahman alKharibiy. Ia lahir pada tahun $126 \mathrm{H}$ dan wafat pada tahun $213 \mathrm{H}$. Dalam periwayatan hadis ia termasuk tingkatan ke 9. Menurut Ibn Hajar dan al-Dzahabi ia memiliki derajat Siqah.

4. 'Abd al-Wahid bin Ayman. Dalam kitab Ruwāt al-Tahdīììn disebutkan nama lengkapnya adalah Abdul Wahid bin Aiman alQarsyi al-Makhzumi, Abu al-Qasim al-Makki. Dalam periwayatan hadis ia termasuk pada tingkatan ke 5. Menurut Ibn Hajar ia memiliki derajat $l \bar{a} b a$ 'sa bihi. Sementara al-dzahabi menempatkannya pada derajat Siqah.

${ }^{13}$ Maktabah Shamilah. 
5. Ayman. Nama lengkapnya adalah Ayman al-Habasyi al-Makki al-Qarsyi al-Makhzumi mawlā Abdullah bin Abi Amr bin Umar bin Abdullah al-Makhzumi. Ia termasuk perawi hadis tingkatan ke 4. Ibnu Hajar dan al-Dzahabi melihatnya sebagai seorang yang memiliki derajat Siqah.

Menurut Salamah Noorhidayati, semua periwayat hadis Gadir Khum yang diriwayatkan al-Nasa'i dari jalur Sa'd bin Abi Waqqas tidak ada yang dicela oleh para kritikus hadis. Dan karena salah seorang perawi, yakni 'Abd al-Wahid bin Ayman, berpredikat là ba'sa bih, maka sanad ini berkualitas hasan. ${ }^{14}$

Kekuatan sanad al-Nasa'i ini bisa saja semakin meningkat bila dikaitkan dengan adanya pendukung yang berupa syahid dan mutabi'. Sa'd bin Abi Waqqas yang menjadi periwayat pertama dari sanad ini mempunyai banyak syahid, di antaranya adalah Abu Ayyub al-Anșari, al-Barra' bin 'Azib, Buraidah, Abu Syarihah, Zaid bin Arqam dan Ali bin Abi Thalib. Selain itu, Aiman yang merupakan perawi kedua mempunyai mutabi', yakni Abd alRahman bin Sabid yang menjadi periwayat kedua untuk sanad yang diriwayatkan Ibn Majah. Secara keseluruhan, dukungan yang berasal dari sanad-sanad Ibn Majah, Ahmad, al-Tirmidhi dan Ibn Hibban akan semakin menambah kekuatan sanad al-Nasa'i bila ternyata semua sanad dari para mukharrij itu berkualitas sahih. ${ }^{15}$

Mengenai ketersambungan sanad-nya, ia menegaskan bahwa hadis Gadir Khum riwayat al-Nasa'i dari Sa'd bin Abi Waqqas termasuk dalam kategori hadis marfu' dengan sanad yang mutasil karena di dalam kitab tārīkhal-ruwāat disebutkan bahwa para perawi hadis ini ada hubungan guru dan murid. Selain itu, dilihat dari tahun kelahiran dan tahun wafatnya, mereka hidup sezaman. ${ }^{16}$

Secara umum, ia menyimpulkan bahwa hadis Gadir Khum riwayat al-Nasa'i dari Sa'ad bin Abi Waqqas diriwayatkan oleh

\footnotetext{
${ }^{14}$ Salamah Noorhidayati, Hadis Gadir Khum dalam Perspektif Sunni dan Syiah (Telaah Ma'nawi al-Hadis), Laporan Penelitian Individual, Proyek Peningkatan Perguruan Tinggi/IAIN Tulungagung, 2014, h. 93.

${ }^{15}$ Ibid., h. 94.

${ }^{16}$ Ibid., h. 92 .
} 
periwayat yang thiqah (hanya satu yang berkualitas $l \bar{a} b a$ 'sa bih), memiliki sanad muttasiil, dan termasuk hadis marfu'. Dengan demikian, sanad hadis ini berkualitas hāsan liżatih, dan karena ada penguatan dalam semua tingkatannya, maka hadis ini menjadi sahih ligairih. ${ }^{17}$ Selanjutnya ia menegaskan, memperhatikan banyaknya jumlah perawi yang meriwayatkan hadis ini, maka hal ini mengindikasikan bahwa hadis Gadir Khum termasuk ke dalam kategori hadis mutawatir. ${ }^{18}$

Mengenai matan hadis Gadir Khum, pada prinsipnya tidak ada masalah. Secara redaksional hadis ini tidak kontradiktif dengan akal sehat, sejarah, kaidah kebahasaan, maupun prinsip dasar alQur'an. Hanya saja, dalam hadis-hadis Gadir Khum ini memang terdapat perbedaan redaksi. Namun perbedaan redaksi ini tidak bisa menggugurkan kenyataan bahwa Nabi pernah berkhutbah di Gadir Khum tentang ke-mawla-an Ali di hadapan ratusan/ribuan para Sahabatnya. ${ }^{19}$

Menurut Syarafuddin al-Musawi (salah seorang ulama Syiah), ${ }^{20}$ kemutawatiran hadis ini didukung oleh beberapa faktor. Di antaranya, pertama, kebiasaan/hukum alamiyah. Setiap peristiwa besar dalam sejarah yang diperankan oleh pemimpin besar suatu bangsa dan dilakukannya di hadapan penglihatan dan pendengaran beribu-ribu umatnya yang berkumpul dari berbagai tempat akan menjadi ingatan kolektif bangsa tersebut. Apalagi bila berita itu sangat dijaga dan dipelihara secara seksama oleh keluarga sang pemimpin dan pengikut-pengikut mereka yang setia pada setiap generasi sehingga ia tersebar secara meluas di mana-mana dan di setiap penjuru.

Kedua, kaum Syiah menjadikan hari ke 18 Dhul Hijjah, hari ketika Nabi menyampaikan hadis Gadir Khum, sebagai hari raya setiap tahunnya. Mereka berdatangan ke masjid guna melaksanakan shalat, membaca al-Qur'an, dan membaca do'a-do'a ma'tur sebagai tanda syukur kepada Allah yang telah menyempurnakan agama-Nya

\footnotetext{
${ }^{17}$ Ibid., h. 95.

${ }^{18}$ Ibid., h. 82.

${ }^{19}$ Ibid., h. 96-100.

${ }^{20}$ A. Syarafuddin al-Musawi, al-Murāja 'āt..., h. 265-274.
} 
dengan menetapkan Imamah bagi Amirul Mukminin, Ali bin Abi Thalib. Ahli-ahli pidato mereka terus-menerus memperingati dan menyebut-nyebut Gadir Khum di setiap tempat dan waktu sambil membawakan sanad-nya. Demikian juga yang dilakukan para penyairnya. Tiada alasan sama sekali untuk meragukannya sebagai hadis yang mutawatir sebab kesungguhan mereka dalam menghafalnya dengan lafal aslinya dan perhatian mereka dalam menjaga dan menyiarkannya telah mencapai puncak yang tertinggi. ${ }^{21}$

Ketiga, kemutawatiran hadis ini didukung dengan sikap Ali ketika menjadi khalifah yang menanyakan kesaksian para Sahabat yang mendengar langsung khutbah Nabi di lembah Khum itu. Dalam suatu kesempatan pada masa kekhalifahannya di suatu tempat yang bernama Rahbah, ada sekelompok orang datang menemui Ali dan mengatakan, "Assalāmu 'alaikum wahai mawlaku." Imam Ali lalu bertanya, "Bagaimana Aku dapat menjadi mawla-mu sementara anda sekalian adalah kaum Arab?" Mereka menjawab, "Kami mendengar Rasulullah Saw. bersabda pada hari Gadir Khum: Siapa yang Aku adalah mawla-nya, maka ini [Ali] adalah mawla-nya. ${ }^{22}$

Setelah kita mengetahui derajat hadis Gadir Khum, yakni hadis ini mencapai derajat mutawatir, pertanyaannya adalah apakah kedua kelompok Syiah dan Sunni otomatis menyepakati kepemimpinan Ali bin Abi Thalib pasca wafatnya Nabi Saw., sehingga tidak ada lagi perbedaan prinsipil di antara keduanya, ataukah masih ada ruang perbedaan pendapat dalam memaknai

${ }^{21}$ Peringatan Hari Raya ini di kalangan Syiah dikenal dengan Hari Raya al-Gadir. Menurut mereka, Hari Raya al-Gadir adalah hari kebahagiaan dan kerelaan karena adanya kasih sayang, yang dengannya Tuhan menyempurnakan agama-Nya. Lihat M. B. Ansari, What Happened? Peristiwa Seputar Haji Terakhir..., h. 147-151.

${ }^{22}$ Mengenai riwayat kesaksian ini, ada beberapa versi hadis tentangnya. Versi hadis mengenai kesaksian orang-orang Arab ini terdapat dalam Imam Ahmad, Musnad Ahmad, juz 51, h. 327 (Maktabah Shamilah). Dalam riwayat lain dijelaskan bahwa yang memberi kesaksian terhadap permintaan Imam Ali tersebut berjumlah 30 orang, lihat Imam Ahmad, Musnad Ahmad juz 42, 106 (Maktabah Shamilah). Dalam riwayat yang lain lagi disebutkan bahwa jumlah mereka 12 orang, lihat Us'ud al-Ghabah, juz 1, h. 234 (Maktabah Shamilah). 
hadis ini, sehingga boleh jadi keduanya menyepakati derajat hadisnya namun berselisih pendapat dalam memahami kandungan maknanya. Untuk menjawab beberapa pertanyaan ini, penulis akan menyajikan pemahaman kedua kelompok terhadap hadis ini.

\section{Pemahaman Sunni dan Syiah terhadap Hadis Gadir Khum}

Uraian berikut ini akan menyajikan pemahaman kedua kelompok (Sunni dan Syiah) terhadap hadis Gadir Khum agar diketahui apakah ada kesamaan pemahaman atau terdapat perbedaan pemahaman di antara keduanya. Jika ada perbedaan, di mana letak perbedaan pendapat keduanya. Dari kalangan Sunni, penulis bersandar pada kitab Fath al-Bari dan Syarah Sunan Ibn Majah. Sementara dari kalangan Syiah, penulis bersandar pada kitab al-Muraja'at.

Ibn Hajar dalam Fath al-Bari, ketika menyinggung perkataan Nabi: "Engkau (Ali) di sisiku sama seperti posisi Harun di sisi Musa" (anta minnī bimanzilati hārūn min mūsā), berkata bahwa Harun tidak menjadi khalifah Musa kecuali dalam masa hidup Musa bukan setelah kematian Musa karena Harun wafat sebelum Musa. Pendapat ini dikemukakan oleh al-Khațabi.

Menurut al-Tibī, hadis anta minn̄̄ bimanzilati hāarūn min $m \bar{u} s \bar{a}$ ini mengandung penyerupaan posisi yang masih samar maksudnya, lalu diperjelas dengan perkataan Nabi selanjutnya: illa annahu lā nabiyya ba'dī. Dengan penjelasannya ini dapatlah diketahui bahwa hubungan keduanya (Nabi dan Ali) bukanlah hubungan kenabian (nubuwwah) melainkan hubungan di bawahnya, yakni hubungan kekhalifahan (khilafah). Dan ketika Harun, yang diserupakan ini, menjadi khalifah pada masa hidup Musa, ini menunjukkan atas kekhususan khilafah Ali bagi Nabi semasa hidup Nabi pula. Mengenai hadis man kuntu mawlāh fa'aliyyun mawlāh, hadis ini diriwayatkan oleh al-Tirmidhi dan al-Nasa'i dengan jalur sanad yang banyak sekali. Kebanyakan dari sanad-nya adalah sahih dan hasan. ${ }^{23}$

${ }^{23}$ Ibn Hajar, Fath al-Bari, bab Manaqib 'Ali bin Abi Talib, juz 11, h. 5 (Maktabah Shamilah). 
Dalam Syarah Sunan Ibn Majah dijelaskan bahwa posisi Harun di sisi Musa adalah sebagai menteri, karenanya ia tidak menunjukkan keutamaan dan keterdahuluannya atas Abu Bakar dalam soal khilafah karena khilafah bukanlah menteri. Perkataan ini hanya menunjukkan keutamaan Ali bin Abi Thalib atas selainnya, dan tidak menunjukkan penunjukannya sebagai khalifah setelah Nabi karena Nabi mengucapkan hal ini pada Ali ketika Ali menggantikan Nabi di Madinah pada saat perang Tabuk. Ditambah kenyataan bahwa Harun, yang diserupakan dengan Ali, tidak menjadi khalifah setelah Musa bahkan Harun wafat pada masa hidup Musa.

Dikatakan dalam al-Nihāyah, kata mawla mempunyai banyak arti. Di antaranya pemimpin, pemilik, tuan, pemberi, pembebas, penolong, pecinta, anak laki-laki paman, sekutu, ipar laki-laki, dan budak. Hadis man kuntu mawlāh fa'aliyyun mawlah mengandung makna seperti yang disebutkan ini. Imam Syafi'i berpendapat, kata mawla mempunyai arti pelindung Islam seperti firman Allah: "Yang demikian itu karena sesungguhnya Allah adalah pelindung orang-orang yang beriman, dan karena sesungguhnya orang-orang kafir itu tiada mempunyai pelindung." (QS. Muhammad [47]: 11). ${ }^{24}$

Dengan makna mawla seperti dikemukakan Imam Syafi'i ini, kaum Sunni berpendapat bahwa asbab al-wurud hadis ini tidak bisa dilepaskan dari peristiwa pengiriman delegasi ke Yaman di bawah pimpinan Ali bin Abi Thalib untuk mengumpulkan zakat dan menyerahkan jizyah, yakni pada tahun $10 \mathrm{H}$. sebelum pelaksanaan Haji Wada'. Pada saat di Yaman, beberapa Sahabat yang ikut bersamanya mengecam beberapa tindakan Ali yang dinilai terlalu berlebihan dan mengambil bagian dari seperlima jizyah sebelum diserahkan kepada Rasulullah Saw. Setelah kembali ke Madinah mereka melaporkan hal tersebut kepada Rasulullah Saw. tetapi Rasulullah tidak berkenan atas sikap mereka yang menjelekjelekkan Ali.

${ }^{24}$ Syarah Sunan Ibn Majah, bab 'Ittiba' al-Sunnah, juz 1, h. 12 (Maktabah Shamilah). 
Kasak-kusuk para Sahabat, khususnya dari para prajurit terhadap Ali semakin menjadi-jadi dan semakin tersiar saat pelaksanaan Haji Wada'. Oleh karena itu, setelah selesai pelaksanaan ibadah haji dalam perjalanan pulang ke Madinah, Rasulullah Saw. berkhutbah di depan kaum Muslimin yang isinya mengenai keutamaan, keadilan, dan sifat amanah Ali. Dengan demikian, menurut Ibn Katsir dalam al-Bidayah, seperti dikutip Salamah Noorhidayati, hadis Gadir Khum ini berisi peringatan Rasulullah Saw. kepada umatnya untuk saling mencintai dan menolong (ber-wala') dan tidak boleh saling membenci dan memusuhi, walaupun hadis ini ditujukan kepada orang-orang yang saat itu tidak suka dan tidak setuju atas beberapa keputusan dan sikap Ali. ${ }^{25}$

Jadi makna mawla menurut kaum Sunni adalah pelindung atau penolong. Sementara menurut Syiah, makna mawla adalah pemimpin/khalifah. Mereka berpendapat bahwa makna hadis Gadir Khum tak mungkin bisa ditakwil. Maknanya jelas bahwa hadis itu menunjukkan pengangkatan Ali bin Abi Thalib sebagai khalifah Nabi. Syarafuddin al-Musawi menegaskan, hadis ini sudah jelas maknanya, dan upaya menakwilkannya merupakan perbuatan menyesatkan dan keterlaluan. Ia beralasan:

Mengapa Rasulullah menahan beribu-ribu pengikutnya untuk tidak meneruskan perjalanan? Mereka dihentikan di tengah terik matahari padang pasir. Mengapa beliau bersungguh-sungguh memanggil kembali yang telah berada di depannya, dan menunggu mereka yang tertinggal di belakang? Mengapa ia menempatkan mereka semua di padang terbuka yang tanpa air dan tanaman? Mengapa beliau mengangkat lengan Ali sehingga nampak jelas warna putih ketiaknya, lalu berkata, “... siapa yang (mengakui) aku sebagai mawla-nya, maka dia ini adalah mawla-nya juga.” Mengapa pula Rasul berdo'a, "Ya Allah, kasihilah siap yang memperwalikannya, dan musuhilah siapa yang memusuhinya."

Mengapa beliau menyejajarkan Ahlul Bait dengan alQur'an, dan menjadikan mereka sebagai contoh teladan? Apa yang menyebabkan perhatian yang begitu besar dari Nabi yang amat bijaksana ini? Kepentingan apa yang membutuhkan segala pendahuluan seperti ini? Sasaran apa yang hendak dituju beliau

${ }^{25}$ Salamah Noor hidayati, Hadis Gadir Khum..., h. 105-108. 
dalam peristiwa amat penting ini? Apakah Nabi Saw. hanya hendak mengatakan tentang pembelaan Ali atau pertolongannya bagi kaum Muslimin, atau tentang persahabatannya dengan mereka? Tidak mungkin hanya sekadar ini. Yang patut kita katakan adalah tidak ada sesuatu pun yang dimaksudkan beliau selain dari penetapan Ali sebagai penggantinya sepeninggalnya. ${ }^{26}$

Hadis Gadir Khum ini, menurut orang-orang Syiah, dilatarbelakangi oleh turunnya ayat QS. al-Ma'idah [5]: 67, yang artinya:

"Hai rasul, sampaikanlah apa yang diturunkan kepadamu dari Tuhanmu, dan jika tidak kamu kerjakan (apa yang diperintahkan itu, berarti) kamu tidak menyampaikan amanat-Nya. Allah memelihara kamu dari (gangguan) manusia. Sesungguhnya Allah tidak memberi petunjuk kepada orang-orang yang kafir."27

Mereka meyakini adanya hubungan erat antara turunnya ayat tersebut pada hari Gadir Khum dengan kepemimpinan Ali. Di antara hal yang menguatkan bukti mengenai ini adalah kenyataan bahwa shalat sudah didirikan sebelum turunnya ayat itu, zakat pun sudah diwajibkan, puasa sudah disyari'atkan, haji sudah dilakukan, yang halal sudah jelas, yang haram sudah jelas, syari'at sudah teratur, hukum-hukumnya pun sudah tertib. Maka urusan apa lagi yang masih harus ditekankan Allah, selain pelimpahan kepemimpinan? Persoalan apakah gerangan yang pengumumannya oleh Nabi dikuatirkan akan menimbulkan fitnah, selain soal khilafah? ${ }^{28}$

Demikianlah perbedaan pemahaman kedua kelompok ini mengenai kandungan makna hadis Gadir Khum. Dengan demikian, dapat dikatakan bahwa letak perbedaan keduanya ada pada

${ }^{26}$ A. Syarafuddin al-Musawi, al-Muraja'at..., h. 276-280.

27 Keterangan mengenai kaitan hadis Gadir Khum dengan QS. alMa'idah: 67 ini terdapat juga dalam kitab-kitab tafsir kalangan Sunni, seperti bisa dibaca dalam 'Abd al-Rahman Jalal al-Din al-Suyuti, al-Durr al-Manthur fi alTafsir al-Ma'thur, juz 3 (Beirut: Dar al-Fikr, 2009), h. 117. Selain al-Durr alManthur fi al-Tafsir al-Ma'thur, menurut Syarafuddin al-Musawi, kitab-kitab tafsir Sunni yang memuat keterangan ini adalah Asbab al-Nuzul oleh al-Wahidi, Nuzul al-Qur'an oleh al-Hafidz Abu Nu'aim, al-Fara'id oleh Ibrahim alHamwini, al-Kabir oleh Abu Ishaq al-Ṡa'labi. Lihat A. Syarafuddin al-Musawi, al-Muraja'at..., h. 266.

${ }^{28}$ A. Syarafuddin al-Musawi, al-Muraja 'at..., h. 265-266. 
pemahaman terhadap kata mawla. Sunni berpendapat bahwa kata itu bermakna pelindung/penolong, sementara Syiah berpendapat bahwa kata itu bermakna khalifah/pemimpin. Perbedaan pemahaman ini otomatis juga mengandung konsekuensi yang berbeda. Jika dipahami sebagai pelindung/penolong, maka hadis ini sama sekali tidak berurusan dengan masalah kepemimpinan pasca Rasul Saw. Ia hanya mengingatkan bahwa sosok Ali adalah pribadi agung yang mesti dicintai sebagaimana mereka mencintai Nabinya. Sementara jika dimaknai khalifah/pemimpin, maksudnya jelas, Ali adalah khalifah setelah Nabi.

Pada gilirannya, karena kata itu hanya dimaknai sebatas pelindung/penolong, maka dalam urusan kepemimpinan, kaum Sunni membangun sistem peralihan kekuasaan berdasarkan sistem musyawarah (syura). ${ }^{29}$ Sementara di sisi lain, karena kata itu dimaknai sebagai khalifah/pemimpin, maka dalam urusan kepemimpinan, kaum Syiah membangun sistem peralihan kekuasaan berdasarkan sistem penunjukan. ${ }^{30}$

${ }^{29}$ Sistem ini terutama terlihat dalam suasana pengangkatan Abu Bakar sebagai khalifah sepeninggal Nabi Saw. di Saqifah Bani Sa'idah. Saat itu ada tiga kelompok yang muncul ke permukaan: pertama, kelompok Ali bin Abi Thalib dan Zubair serta kawan-kawannya. Kelompok ini terdiri dari Salman al-Farisi, Abu Dzar al-Ghiffari, Miqdad bin Aswad, Ammar bin Yasir, Khuzaimah bin Tsabit, Ubai bin Ka'ab, dan lain-lain. Calon dari kelompok ini adalah Ali bin Abi Thalib. Kedua, kelompok kaum Anshar yang melakukan pertemuan tersendiri di Saqifah. Calon dari kelompok ini adalah Sa'id bin Ubadah. Ketiga, kelompok Umar, Abu Bakar, dan Abu Ubaidah. Termasuk kelompok ini adalah Mughirah bin Syu'bah dan Abdur Rahman bin Auf. Calon dari kelompok ini adalah Abu Bakar. Musyawarah kaum Muslimin di Saqifah Bani Sa'idah untuk memilih pengganti Nabi setelah melalui perdebatan pelik menghasilkan Abu Bakar sebagai khalifah pengganti Nabi. Lebih lanjut lihat O. Hashem, Saqifah Awal Perselisihan Umat, cet. 3 (Jakarta: al-Muntazhar, 1994), h. 106-112 \& 192-196.

${ }^{30}$ Murtadha Muthahhari mengatakan bahwa persoalan kepemimpinan (Imamah), sebagaimana persoalan kenabian, berada di luar kontrol manusia. Seorang Imam tidak dapat dipilih dengan keputusan manusia. Seperti seorang Nabi, ia ditunjuk oleh peraturan Ilahi. Satu-satunya perbedaan adalah Nabi punya hubungan langsung dengan Allah, sedangkan seorang Imam ditunjuk oleh seorang Nabi dengan menerima perintah-perintah Ilahi. Jika Imamah dari Imam Ali itu terbukti, Imamah dari para Imam lainnya dapat didasarkan pada wewenang deklarasi yang dibuat oleh Imam terdahulu. Lihat Murtadha Muthahhari, Imamah dan Khilafah, penerjemah: Satrio Pinandito, cet. 1 (Jakarta: Firdaus, 1991), h. 7071. 


\section{E. Menyikapi Perbedaan}

Penulis tidak akan menyimpulkan perbedaan ini dengan cara memilih salah satu dari kedua pemahaman yang berbeda ini karena model penyimpulan seperti ini akan berarti menafikan identitas salah satu pihak. ${ }^{31}$ Menyimpulkan bahwa pemahaman Syiah yang benar sama artinya dengan memaksa kaum Sunni menerima premispremis utama ke-Syiah-an yang di antaranya adalah meyakini Imam Ali sebagai pemimpin setelah Nabi. Penerimaan ini tidak mungkin dilakukan kaum Sunni karena ia akan menggugurkan ke-Sunni-an mereka. Sebaliknya, menyimpulkan bahwa pemahaman Sunni yang benar sama artinya dengan memaksa kaum Syiah menerima premispremis utama ke-Sunni-an yang di antaranya adalah Nabi tak pernah menunjuk penggantinya sebagai pemimpin setelahnya. Penerimaan ini juga tidak mungkin dilakukan kaum Syiah karena ia akan menggugurkan ke-Syiah-an mereka.

Yang mungkin dilakukan adalah membiarkan keduanya berbeda dengan identitasnya masing-masing, bukan meleburnya menjadi satu mazhab yang menyebabkan ketiadaan identitas keduanya. Alasannya, selain hampir tidak mungkin meleburnya menjadi satu karena keduanya lahir dari, dan mempunyai, tradisi pemikiran yang berbeda, perbedaan keduanya bukanlah perbedaan usuliy (pokok) yang menyebabkan keduanya berada di luar batas keislaman, ${ }^{32}$ tetapi perbedaan furu' (cabang), ${ }^{33}$ yang masih dalam batas kewajaran.

${ }^{31}$ Lihat kesimpulan Salamah Noorhidayati dalam penelitiannya tentang Hadis Gadir Khum dalam Perspektif Sunni dan Syiah..., h. 135. Bandingkan dengan Ahmad Khoirul Fata dan M Hukkam Azhadi, "Menyoal Otentisitas Hadis Dua belas Khalifah," Al-Qalam, Vol 30, No 3, 2013

${ }^{32}$ Yang jarang diingat oleh kedua kelompok Syiah dan Sunnah adalah bahwa keduanya mempunyai kesamaan uṣuliy, yakni bahwa keduanya mengakui keesaan Allah dan kerasulan Nabi terakhir Muhammad Saw., shalat lima kali sehari, puasa sepanjang bulan Ramadhan, menunaikan zakat, dan berhaji ke Baitullah Mekkah dan sekitarnya bagi yang mampu. Lihat M. Quraish Shihab, Sunnah Syiah Bergandengan Tangan! Mungkinkah? Kajian atas Konsep Ajaran dan Pemikiran..., h. 237; baca juga Abu Bakar Aceh, Syiah Rasionalisme dalam Islam..., h. 26-28.

${ }^{33}$ Uraian menarik mengenai perbedaan furu'iyy dalam bidang fiqh, lihat M. Quraish Shihab, Sunnah Syiah Bergandengan Tangan! Mungkinkah? Kajian atas Konsep Ajaran dan Pemikiran..., h. 243-255. 
Karena itu, agar tercipta ukhuwwah Islamiyyah, keduanya mesti didekatkan dengan cara merawat persamaan, bukan dijauhkan dengan cara membesar-besarkan perbedaan, seolah-olah yang satu menjadi musuh bagi yang lain. Walaupun upaya pendekatan ini tidak mudah dilakukan terutama oleh mereka (baik dari Syiah maupun Sunnah) yang sudah menutup diri dan enggan melakukan dialog, upaya ini harus terus disuarakan karena terciptanya pendekatan yang diinginkan itu akan banyak mendatangkan manfaat, bukannya madarat, bagi Islam dan kaum Muslimin.

Dalam upaya pendekatan ini, menarik mempertimbangkan tawaran Quraish Shihab berikut: ${ }^{34}$

Pertama, kita mesti memahami mazhab sendiri dan juga memahami mazhab lain. Karena jika tidak mendalami mazhab sendiri, sangat mungkin kita menyalahkan orang lain atas nama mazhab kita, padahal mazhab kita dapat membenarkannya. Atau jika tidak punya pengetahuan yang cukup tentang mazhab lain, kita cenderung menyalahpahami mereka.

Kedua, kita harus menghindari hal-hal yang dapat melukai perasaan mazhab lain. Sunni akan sangat tersinggung jika Khulafa' al-Rasyidun, atau para isteri Nabi (Ummahat al-Mu'minin), atau para Sahabat Nabi dimaki-maki. ${ }^{35}$ Demikian juga, Syiah akan sangat tersinggung jika mazhabnya dinilai sesat apalagi dinilai kafir. ${ }^{36}$ Kecenderungan memaki-maki dan menyesatkan ini harus

34 M. Quraish Shihab, Sunnah Syiah Bergandengan Tangan! Mungkinkah? Kajian atas Konsep Ajaran dan Pemikiran..., h. xviii-xiii.

${ }^{35}$ Mungkin di antara Khulafa' al-Rasyidun atau Sahabat Nabi Saw. yang paling banyak mendapat penilaian negatif dari kelompok Syiah adalah Umar bin Khaththab. Di kalangan Sunni Umar tidak saja dihormati dan disegani namun juga disepakati sebagai Amir al-Mu'minin yang paling berhasil. Kaum Sunni menilai bahwa masa Umar adalah masa keemasan Islam. Tidak heran, bila reformis kegamaan, sosial, dan politik Islam harus mencari model klasik, ia akan bersemangat menyebut masa Umar. Mereka, para reformis Muslim, sangat mengagumi Umar tidak saja karena ia menauladani bagaimana menangkap semangat Islam secara menyeluruh, tetapi juga karena ia berhasil menciptakan masyarakat yang menurut jargon-jargon modern dinamai demokratis dan sosialis. Lihat Nurcholish Madjid (ed.), Khazanah Intelektual Islam, cet. 4 (Jakarta: Bulan Bintang, 2007), h. 5-6.

${ }^{36}$ Baca kembali catatan kaki nomor 3 tentang kelompok Syiah Gulāt yang dinilai al-Bagdadi tidak termasuk kelompok Islam. Sayangnya, menurut 
segera dihentikan. Keduanya harus saling memahami hal ini. Sayangnya, meskipun hal ini telah disepakati oleh ulama kedua pihak dalam dialog mereka, sebagian dari umat kedua mazhab belum melaksanakan kesepakatan itu.

Ketiga, hendaknya mencari titik persamaan, bukan memperbesar perbedaan, denganmenghindari buruk sangka dan menghilangkan sikap apriori terhadap kelompok lain. Contohnya, sikap kaum Sunni yang tidak menggubris tuduhan Syiah meyakini al-Qur'an yang beredar di seluruh dunia telah diubah oleh para Sahabat karena jauh sebelum tuduhan ini muncul, tokoh Imāmiyyah, Abu Ali al-Fadhel, telah membantahnya. Demikian juga tokoh Imāmiyyah kontemporer, Thabathaba'i, juga membuktikan kebatilan tuduhan tersebut. Bagi yang tak ingin melihat titik persamaan, mereka bukan saja tidak menggubris sanggahan tokoh-tokohSyiah ini, namun juga akan selalu menyuarakan tuduhan itu.

Keempat, memang ada sekian pandangan kedua pihak, Syiah dan Sunnah, yang tidak dapat dipertemukan, tetapi masingmasing pihak hendaknya memahami sikap pihak lain. Salah satu persoalan yang disepakati untuk tidak disepakati antara Syiah dan Sunnah adalah soal Imamah. Masing-masing mempertahankan pendapatnya dengan menggunakan ayat al-Qur'an dan Sunnah Nabi Saw. tetapi dengan riwayat atau penafsiran yang berbeda. Dalam hal ini, adalah terpuji jika masing-masing memahami alasan masingmasing tanpa memaksakan pihak lain menganutnya.

Kelima, perlu ditegaskan di sini bahwa upaya pendekatan ini tidak bermaksud menjadikan keduanya menyatu, namun mengundang mereka memahami sikap masing-masing secara objektif dan adil lalu bergandengan tangan tanpa melebur identitas. Biarlah yang Sunni tetap Sunni dan yang Syiah pun tetap Syiah. Keduanya berjalan seiring ke depan menuju kejayaan umat.

Syarafuddin al-Musawi, pendirian Syiah Gulāt ini telah dipandang oleh sebagian besar kaum Sunni sebagai mewakili semua kelompok Syiah. Mereka (sebagian besar kaum Sunni) lalu membenci semua kelompok Syiah tanpa membedabedakan antara yang baik dan yang jahat, atau antara yang bersalah dan yang tidak. Lihat A. Syarafuddin al-Musawi, Isu-isu Penting Ikhtilaf Sunnah Syiah, penerjemah: Mukhlis, cet. 4 (Bandung: Mizan, 1994), h. 205. 
Demikianlah beberapa butir pokok pikiran Quraish Shihab dalam upaya mendekatkan kedua mazhab Syiah dan Sunnah. Dalam upaya ini kita tak mungkin melupakan jasa besar Mahmud Syaltut (Rektor al-Azhar tahun 1958 M.) Ketika beliau mengeluarkan fatwa yang saat itu menggemparkan dunia Islam:

“...mazhab Ja'fariyyah yang terkenal sebagai salah satu mazhab Syiah Imamiyyah Ithna 'Asyariyyah adalah mazhab yang kita diperbolehkan beribadah dengan mazhab itu sebagaimana dengan mazhab-mazhab lain dari Ahl al-Sunnah wa al-Jama'ah.",37

Upaya ini tidak hanya disuarakan secara individualnamun juga secara kelembagaan. Di Makkah pada 20 Oktober 2006 M., dengan dipayungi Organisasi Kerjasama Islam, telah dilangsungkan pertemuan antar ulama Irak yang bermazhab Syiah dan Sunnah. Pertemuan tersebut mencetuskan piagam bersama yang terdiri dari sepuluh butir. Tiga di antaranya adalah (1) seorang Muslim adalah siapa yang bersaksi bahwa tiada Tuhan selain Allah dan Muhammad adalah Rasul-Nya. Termasuk dalam hal ini adalah seluruh pengikut mazhab Sunnah dan Syiah; (2) darah dan harta benda kaum Muslim serta kehormatan mereka haram (diganggu); (3) tempat-tempat peribadatan memiliki kesucian. Ini termasuk masjid, al-Husainiyat, dan tempat peribadatan non-Muslim. ${ }^{38}$

Lalu pada 20-22 Januari 2007, Muktamar Doha tentang dialog antar mazhab dalam Islam, yang diselenggarakan oleh Universitas Qatar bersama Universitas al-Azhar Mesir dan Lembaga Internasional untuk Pendekatan Antarmazhab Islam yang berpusat di Iran, menghasilkan sepuluh rambu penting. Di antaranya, mengajak para pemimpin agama dari kalangan Sunnah dan Syiah agar memelihara batas-batas dan norma-norma interaksi dengan pihak lain, dan tidak mengizinkan adanya penyebaran tasyayyu' (paham Syiah) di negeri-negeri penganut aliran Sunnah,

${ }^{37}$ Lihat Abu Bakar Aceh, Syiah Rasionalisme dalam Islam..., h. 232-233.

${ }^{38}$ Lihat M. Quraish Shihab, Sunnah Syiah Bergandengan Tangan! Mungkinkah? Kajian atas Konsep Ajaran dan Pemikiran..., h. 264-266. 
tidak juga penyebaran tasannun (paham Sunnah) di negeri-negeri penganut aliran Syiah. ${ }^{39}$

Beberapa upaya ini mesti dirawat dan dipertahankan agar kedua kelompok tersebut tak selalu tersandera peristiwa politik masa lalu, dan tidak selalu menoleh ke belakang. Cukuplah peristiwa itu memperkaya wawasan agar mereka bijak dalam bersikap dan mengambil tindakan. Saat ini mereka harus mengembangkan semangat ukhuwwah Islamiyyah untuk menghadapi berbagai tantangan politik, sosial, dan budaya demi kejayaan umat Islam.

\section{F. Kesimpulan}

Hadis Gadir Khum menarik dikaji karena hadis ini terdapat dalam kitab-kitab hadis kalangan Sunnah. Hadis Gadir Khum adalah hadis pegangan utama kalangan Syiah yang mempunyai pendirian bahwa sebelum wafat Nabi Saw. telah mengkader dan menunjuk penggantinya, yakni Ali bin Abi Talib, untuk meneruskan risalah kenabiannya. Pertanyaannya, apakah dengan adanya hadis Gadir Khum di kalangan Sunni mereka (kelompok Sunni) juga mengakui Ali sebagai pengganti Nabi Saw. setelah wafatnya.

Jawabannya adalah mereka memang meriwayatkan hadis ini, men-sahih-kannya, bahkan menilainya mutawātir. Namun mereka mempunyai pemahaman berbeda terhadap kata mawla yang ada dalam matan hadis tersebut. Mereka memahami kata tersebut sebagai pelindung. Sementara menurut kalangan Syiah, kata itu bermakna pemimpin. Masing-masing mempunyai argumen. Menyikapi perbedaan pemahaman ini, yang mungkin dilakukan adalah membiarkan keduanya berbeda dalam identitas masingmasing seraya mengupayakan pendekatan keduanya semata-mata untuk kepentingan ukhuwah Islamiyah dan kejayaan umat Islam. []

${ }^{39}$ Lihat M. Quraish Shihab, Sunnah Syiah Bergandengan Tangan! Mungkinkah? Kajian atas Konsep Ajaran dan Pemikiran..., h. 267-268. 


\section{Daftar Pustaka}

Aceh, Abu Bakar, Syiah Rasionalisme Dalam Islam, Solo: Ramadhani, 1988.

Ahmad, Imam, Musnad Ahmad, juz 40, Maktabah Shamilah.

Ahmad, Imam, Musnad Ahmad, juz 42, Maktabah Shamilah.

Al-Baghdadi, al-Farq bayn al-Firaq, Beirut: Dar al-Kutub al'Ilmiyyah, tt.

Al-Hakim, al-Mustadrak 'ala al-Saḥihayn, juz 3, Maktabah Shamilah.

Al-Hakim, al-Mustadrak 'ala al-Sahihayn, juz 3, Maktabah Shamilah.

Al-Musawi, A. Syarafuddin, Isu-isu Penting Ikhtilaf Sunnah Syiah, penerjemah: Mukhlis. Bandung: Mizan, 1994.

Al-Musawi, Syarafuddin, al-Muraja'at, Beirut: ttp., 1982.

Al-Nasa'i, Imam, Sunan al-Nasa'i al-Kubra, juz 5, Maktabah Shamilah.

Al-Suyuti, 'Abd al-Rahman Jalal al-Din, al-Durr al-Manthur fi alTafsir al-Ma'thur, juz 3, Beirut: Dar al-Fikr, 2009.

Al-Tirmidhi, Imam, Sunan al-Tirmidhi, juz 5, Maktabah Shamilah. Ansari, M. B., What Happened? Peristiwa Seputar Haji Terakhir, Jakarta: Al-Huda, tt.

Fata, Ahmad Khoirul dan M. Hukkam Azhadi, "Menyoal Otentisitas Hadis Duabelas Khalifah." Al-Qalam, Vol 30, No 3, 2013

Fata, Ahmad Khoirul, "Hadits Gadir Khum, Mandat Kepemimpinan Untuk Ali?”, Jurnal Studi Islam, Vol II No 3, 2017.

Hajar, Ibn, Fath al-Bari, bab Manaqib 'Ali bin Abi Talib, juz 11. Maktabah Shamilah.

Hashem, O., Saqifah Awal Perselisihan Umat, Jakarta: alMuntazhar, 1994.

Ibn Majah, Imam, Sunan Ibn Majah, juz 1, Maktabah Shamilah.

Madjid, Nurcholish (ed.), Khazanah Intelektual Islam, Jakarta: Bulan Bintang, 2007. 
Muslim, Imam, Sahih Muslim, juz 4. Maktabah Shamilah.

Muthahhari, Murtadha, Imamah dan Khilafah, penerjemah: Satrio Pinandito, Jakarta: Firdaus, 1991.

Noorhidayati, Salamah, "Hadis Gadir Khum dalam Perspektif Sunni dan Syiah (Telaah Ma'nawi al-Hadis)". Laporan Penelitian Individual, Proyek Peningkatan Perguruan Tinggi/IAIN Tulungagung, 2014.

Shadr, M. Baqir, Suksesi Kepemimpinan Pasca Nabi, penerjemah: M. Syukri. ttp.: Yayasan Islam al-Baqir, 1996.

Shihab, M. Quraish, Sunnah Syiah Bergandengan Tangan! Mungkinkah? Kajian atas Konsep Ajaran dan Pemikiran, Tangerang: Lentera hati, 2014.

Siradj, Said Agiel, Ahlussunnah wal Jama'ah dalam Lintas Sejarah. Yogyakarta: LKPSM, 1997.

Syarah Sunan Ibn Majah, juz 1, Maktabah Shamilah.

Usud al-Ghabah, juz 1, Maktabah Shamilah. 